\title{
Determinants of Effective Communication among Undergraduate Students
}

\author{
Roya Anvari ${ }^{1} \&$ Dauda Mohammed Atiyaye ${ }^{1}$ \\ ${ }^{1}$ Department of Human Resource Management, Faculty of Management, Universiti Teknologi Malaysia, Skudai, \\ Johor, Malaysia \\ Correspondence: Roya Anvari, Department of Human Resource Management, Faculty of Management, Universiti \\ Teknologi Malaysia, 81310 Skudai, Johor, Malaysia. Tel: 601-7245-8894. E-mail: roya.anvari@utm.my
}

Received: June 5, 2014 Accepted: July 16, 2014 Online Published: August 17, 2014

doi:10.5539/ies.v7n9p112 URL: http://dx.doi.org/10.5539/ies.v7n9p112

\begin{abstract}
This study aims to investigate the relationship between effective communication and transferring information. In the present correlational study, a cross-sectional research design was employed, and data were collected using a questionnaire-based survey. 46 students were chosen based on random sampling and questionnaires were distributed among respondents in four faculties located in Universiti Teknologi Malaysia, Johor Bahru. To analyze the descriptive statistics of the data, the Pearson coefficient was conducted. The findings of this study illustrated that communication dimensions including proxemics, paralinguistics, chronemics and kinesics have a moderate positive correlation with transferring information. It is concluded that training programs can increase the awareness of the students about the aspects of effective communication.
\end{abstract}

Keywords: proxemics, paralinguistics, chronemics and kinesics

\section{Introduction}

\subsection{Introduce the Problem}

Effective communication assists us to better comprehend an individual or even a scenario, solve variations, develop belief and regard, condition ideas, solve problems, and nurture passion. Fundamentally, what we attempt to present to large audiences and other people will get misinterpreted and trigger discord as well as disappointment within individuals as well as human relationships. With efficient conversation abilities, it becomes easier to interact with people. Efficient conversation is fundamental to succeed in numerous facets of living. Many occupations require powerful conversational abilities. Individuals with enhanced conversation abilities normally have much better social human relationships. Efficient conversation is a crucial social ability enhancing our own conversational skills has its own advantages. Effective communication is essential for creating good relationship with anybody; regardless of age, gender and background. Even though communication with various organizations could be diverse, the fundamental basic concepts stay the same. Problems such as romantic relationship issues can occur whenever people possess poor conversational ability, or even you don't have the abilities in order to communicate efficiently. These abilities consist of crystal clear appearance, great hearing abilities, as well as having the ability to adjust to various circumstances as well as situations. Interaction on its own consists of speech, clearness, actions, body gestures as well as facial expression. To build a good romantic relationship, efficient conversation is very important. The individual we interact with must feel comfortable and also to get the chance to reciprocate comfortably. It is very important to pay attention to and also utilize good body gestures (may become demonstrated through nodding and so on), to make use of the right facial expression and maintain eye contact whenever suitable (respecting feasible social differences). Grown-ups have to display good human relationships with one another so that kids as well as teenagers so the kid may duplicate this particular conduct. It helps to show what exactly is anticipated as well as appropriate within a relationship. Good conversation is needed among everyone (the kid, employees, as well as parents/careers) to avoid misconceptions as well as unneeded concerns. This conversational skill has to be inculcated within children from young so that they will face less problems when they reach higher levels in the society. Besides that, showing that you are present in their situations and having good conversational skills enable you to be aware of whatever problems your kid is dealing with. When conversation succeeds, it's easier to get assistance not only within a family but probably in their careers in later years. 
Actual conversation is essential among students, particularly with regards to Human Resource administrators. Additionally there is a lot of research regarding conversation such as Press Conversation, Conversation Concept as well as, Conversation Individuality. Different types of conversation kinds exist such as spoken conversation (utilizing talk as well as dialect), non-verbal conversation (symptoms), actions, as well as characters. The value of conversation is actually associated with suggestions along with appearance associated with feelings among humans. Conversation performs a large part among individuals especially in discussing suggestions, wishes, desires, emotions and much more. Poor conversation might prevent development of relationship. Conversation must be open ended and delicate, along with being suitable towards the scenario. The quantity of information needed may be adjusted according to different conditions. Nevertheless there is insufficient investigation with regards to conversation issues amongst students.

To attain effective communication, the actual communicator should encode the actual information to suit the connection between sender and also the recipient (Anene, 2006). There are statements that several communicators dismiss the quantity of the specific info that could overwhelm the product. According to Jacques (1987) efficient conversation is divided into three categories which are a known and comprehensive communication structure, a code regulations governing the relations among people occupying various roles and a relationship among people immediately connected with each other. In the classroom organization, business, marketing communications result from the system associated with other types of relationships that impact the high quality from the conversation by itself.

Communication during a business is known as "Internal Communication". It provides almost all conversation during a business. It might be casual or perhaps an official functionality or even division offering conversation in a variety of types to workers. Effective inner communication is essential when dealing with group issues. Great conversations help improve work fulfillment, security, efficiency, as well as earnings and reduce issues and proceeds. Communication with folks beyond the organization is known as "external communication". Effective external communication leads to better sales volume, public credibility, and operational efficiency and company profits (Ahmadian et al., 2011; Nagamani \& Muthuswamy, 2013). It improves overall performance, public goodwill and corporate image. Ultimately, it helps to achieve organizational goals and customer satisfaction. Expansion of the Scope of Communication is classified according to the number of persons (receivers) to whom the message is addressed. Verbal Communication is oral or written. Non Verbal communications are eye contact, facial expression, posture and gestures, time, space and territory. The purpose of this particular research to recognize the consequence of efficient conversation upon transferring information associated with college students within College associated with technologies in Malaysia. Furthermore, the reason for this particular research is to gather as well as evaluate information about how much efficient conversation impacts information transfer among college students.

\section{Literature Review}

Communication is the procedure for exchanging information. Information is transferred through terms, speech, as well as body gestures. Presentation account $7 \%$ of the information disseminated. Expression makes up about $55 \%$ while body gestures makes up about $37 \%$. Communicators, especially associates, should be aware of those information tools, using all of them efficiently, as well as obstacles towards the marketing communications procedure. In order to communicate effectively, it is important to know the active components in the conversation procedure. When we know about all of them, these types of aspects can help all of us strategize, evaluate circumstances, resolve issues, and improve within our function regardless of what our own work may be (Schramm, 1961).

Several theorists have discussed the communication process in ways that have important implications for those involved in informal education programs such as extension work. Aristotle's model (Roberts, 1924); which was thought out since 300B.C. is more about public speaking. This research was associated with conversation "rhetorics" and consists of 3 components inside the procedure. Aristotle's model (Roberts, 1924) emphasizes the actual lengthy desire for conversation. Additionally they reveal which guy has received a great understand associated with what exactly is associated with conversation for any lengthy whilst. And we may question: When we understand a lot concerning the conversation procedure, and when coming from this knowledge for such a long time, why do some of us still have communications issues?

Harold Lasswell, a political scientist, developed a much quoted formulation of the main elements of communication: "Who says what in which channel to whom with what effect." This formulation is the Lasswell's model (Lasswell, 1948). This summation of the communications process has been widely quoted since the 1940s. The point in Lasswell's comment is that there must be an "effect" if communication takes place. 
If we have communicated, we've "motivated" or produced an effect. It's also interesting to note that Lasswell's version of the communication process mentions four parts: who, what, channel, whom. Three of the four parallel parts are mentioned by Aristotle's speaker (who), subject (what), person addressed (whom). Only channel has been added. Most modern-day theorists discuss the four parts of the communication process, but use different terms to designate them. Within Schramm's model (Schraam, 1961), as did Aristotle, conversation usually needs three components; the origin, the actual information and also the location. Preferably, the origin encodes a note as well as transfers this in order to the location through a few stations, in which the information is actually obtained as well as translated. The Riley's model (Riley and Riley 1965), speaks about the value of the actual sociological view within conversation and within method. Both sociologists state this type of view might align the numerous communications as well as person responses for them during an incorporated interpersonal framework as well as procedure. Berlo's model (1960), the last marketing communications product that people will certainly think about may be the SMCR model, developed by Berlo (1960), a communication theorist and advisor. In the guide "The Conversation", Berlo (1960) highlights the value of the actual emotional view in the communications product. The actual four parts of Berlo's SMCR product are resource, information, station, as well as recipient.

Barriers tend to influence on aspects that slow down or even break down the actual constant communications cycle. Through determining the actual obstacles as well as using countermeasures, associates may effectively communicate. Communications is a procedure that starts with the sender. The actual sender offers information essential for objective achievement. The actual sender should make the actual recipient aware of the information. All too often, what is stated is not what is exactly noticed. The actual information is merely the information the actual sender desires to connect towards the receiver. The actual information is generally spoken; however it may also be non-verbal. The receiver needs information to accomplish his/her task. The potency of them frequently engraves the members' capability to pay attention. Regrettably, many people find hearing hard. The receiver should apply management on the conversation procedure. With regards to the receivers, it is necessary for them to make sure that the actual senders determine what the actual receivers would like as well as the reason why they need this.

For instance; a police officer needs to exert good management on information circulation through the routing evaluator as well as the delivery police officer, as the important information might be hidden within the wide range of information which is regularly passed in throughout transportation within overloaded communication process (Berlo, 1960). Active listening is a procedure utilized by the actual recipient in order to help conversation as well as improve overall performance. It takes the actual recipient to become mixed up in the marketing communications procedure. This displays that this recipient noticed the actual information. Still, with regard to crucial information or even complex suggestions, the recommendation is usually inadequate to ensure comprehension. Parroting is actually repeating the received information from the loudspeaker verbatim. This verifies towards the loudspeaker that these terms transported had been the text obtained. It really is favored within confirming invoice associated with regular instructions. However, it still will not make sure the actual recipient comprehend the actual information.

Paraphrasing is actually saying, in your own words, the information from the sender's information towards the sender's fulfillment (Bovee \& Thill, 1992). This ensures clarity of the actual information with regard to each a person and also the sender. Paraphrasing enables you to look at your knowledge of the actual information as well as displays the actual sender, which you took in precisely (i.e. the information and intention had been properly understood). If the receiver takes in information dubiously, the actual sender still has a chance to correct the conversation mistake.

Body language includes a genial handshake, the nice grin or perhaps a comfortable embrace. Body language is actually conversation via easy entire body actions. Time associated with introduction associated with body gestures cannot be exactly or even precisely determined. Nevertheless the utilization of body gestures as a ways of conversation generally exists within all creatures. Accessible fossil proof suggests different types of speech made an appearance somewhere within 1.5 million and 500,000 years ago. The actual aspects associated with speech development are actually complicated because it is actually affected through aspects such as broadly transported means as well as hereditary development (Jay, 1995).

\subsection{Writing}

A brief history associated with composing goes back towards the numerous composing techniques developed within the Earlier Fermeté Age group (late fourth centuries BC) from Neolithic proto-writing. The actual development associated with articles is believed to possess started out proto-writing meaning pictorial 
communications or icons or scribbles which cannot be known as "actual-writing". Symbols are icons created like a conversation device which does not just guarantees better identification but additionally improved longevity from the information. Cave paintings in the earliest of the Pal Eolithic works of art would be the earliest recognized icons. Homo sapiens' very first split in interacting info had been artwork. The actual earliest recognized given artwork is the actual Chauvet Give dating back to 30,000 B. C., Petroglyphs are not however stone designs. These types of Petroglyphs date back to 10,000 B. C., once the Homo-sapiens happen to be proven to obtain the ability of making fence or even designs within the stone surface area. There were also cases of woodcarvings as well as tattoo designs (Jay, 1995).

\subsection{Pictograms}

Pictographs had been the next phase within the development associated with composing. One notable function which sets apart petroglyphs through the pictograms is the fact that petroglyphs just illustrate one occasion, but pictograms narrate a tale concerning the occasion and therefore may be used to communicate a chronology associated with a number of occasions. Pictograms happened to be sighted within the historical past of numerous historic civilizations because about 9000 B. C... The actual pictograms offered method to the actual development associated with the Cuneiform, which is regarded as the first recognized type of created appearance (Jay, 1995). A good ideogram is definitely a more superior version of the pictogram. This is a visible or even visual symbolic representation which signifies a concept. A number of interests around the globe created diverse ideograms to symbolize several suggestions, still because suggestions such as appearance associated with feelings tend to be common within character, so might be numerous ideograms. Ideograms would be the supply of beginning for many from the logographic composing techniques such as the Chinese language characters (Jay, 1995).

Handling of information, communications, views, talk as well as ideas can be carried out through various types of contemporary conversation press, such as the Web, the phone as well as cellulars. A few of the fundamental methods for conversation tend to be through talking, performing, indication dialect, body gestures, contact as well as eye contact. These types of fundamental methods for conversation are more comfortable with transferring information from one to another. There are various kinds of conversations however they could be categorized in to four fundamental kinds. Verbal communication consists of seems, terms, dialect as well as talking. Dialect has been said to get originated in seems as well as actions. There are lots of different languages on the planet. The actual angles associated with dialect development tend to be: sex, course, occupation, physical region, age bracket along with other interpersonal components. Talking is an efficient method of interacting and it is once again categorized in to 2 types; social communication and speaking in public.

Good verbal communication is definitely a part of company conversation. Within a company, you see individuals through numerous age groups, civilizations and backgrounds. Progressive spoken conversation is important, to cope with individuals running a business conferences. Additionally, running a business conversation assurance performs a huge role that whenever done along with progressive conversation abilities can result in achievement. Public Speaking is a spoken conversation where you need to tackle several individuals. Getting yourself ready for a highly effective talk before you begin is essential. In public areas, the actual talk should be ready based on the kind of viewers you are likely to encounter. The information of the talk ought to be genuine and you also should have adequate facts within the subject you have selected with regard to speaking in public. All of the details within your talk should be outlined and the factors ought to be presented within the proper parameters. There are lots of public speaking methods and they should be employed to have an efficient talk.

\subsection{Non-Verbal Communication}

Non-verbal communication requires actual physical methods for communication, such as from the tone of voice, contact, odor as well as entire body movement. Innovation as well as visual non-verbal conversation consists of performance, songs, dances as well as sculpturing. Icons as well as indication dialect is also a part of non-verbal conversation. Body gestures are really a non-verbal method of conversing. Body posture as well as actual physical contact with provides a large amount of information. Body posture is important if you are interacting by speaking to somebody. Clasped hands as well as closed hips and legs are a few of the actual indicators communicated with an entire body position. Actual physical contact such as, trembling fingers, pressing, patting as well as coming in contact with conveys the sensation associated with closeness. Facial expressions, actions as well as eye contact are various ways associated with conversation. Reading through facial expression will help you understand an individual better. Written communication is actually composing the text that you wish to connect. Good written conversation is important for people who do business. Written communication is actually employed in numerous various different languages. E-mails, reviews, content articles as well as memos are a few of many ways of written conversation employed while running a business. The actual created conversation could 
be modified as well as changed often prior to it really is disseminated towards the 2nd celebration who the actual conversation is supposed. This really is one of the primary benefits of utilizing composing since the main ways of conversation running a business action. Created conversation is utilized with company also for casual conversation reasons. Cellular text is definitely a sort of casual written communication. Visual communication, the final kind of conversation is the visible conversation. Visible conversation is actually visible screen info, such as topography, digital photography, symptoms, icons and styles. TV as well as videos would be the electric type of visible conversation. Effective communication is important for achievement associated with any business (Anvari et al., 2013). Privately, absolutely nothing can be accomplished without correct conversation. Therefore, building expansive abilities is essential. One should realize that all of the 4 kinds of conversation tend to be essential and another should create expansive abilities out of all means. Expansive press keeps growing every day to ensure clarity and also to get rid of unconformity within the conversation. According to Koontz and O'Donnell (2005) communication is important to all phases of management by every individual within the system and is particularly important in directing and leading any system. This assertion is further explained by McFarland (1994: 56) who observes that communication is a central element in all aspects of life. Lesikar, Pettit and Darsey (1999) say that "communication is the ingredient which makes organization possible". To achieve its objectives, a classroom must have effective communication systems (Figure 1). Merrihue (1980) defines effectiveness of communication "as any initiated behavior on the part of the sender which conveys the desired meaning to the receiver and causes desired response behavior from the receiver" (Merrihue, 1980). Communication effectiveness in the classroom setting involves two or more people (a sender and receiver).

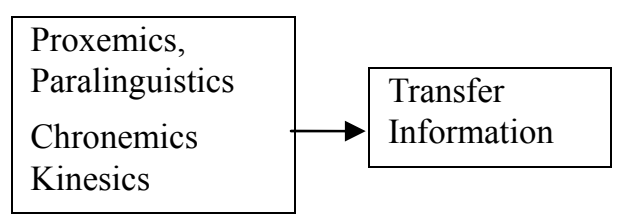

Figure 1. Conceptual framework

\section{Method}

The process of research begins with the research problem statement. This stage explains on the item or what is actually being researched, and states the factors that are being research. The setting of objectives serves the purpose of providing a guideline in acquiring the final results. In the step of data analyzing, quantitative and qualitative analysis has been used. The data analysis method used depends on the data collection methods utilized, which are questionnaire and observation. Through the outcomes of data analysis, the conclusion and recommendation on this research problem can made. After the explanation, researcher will able to complete the research report. The respondents of the study were undergraduate students from different courses at Universiti Technologi Malaysia. In 2014, a total of 50 questionnaires were distributed to students at different courses of the Faculty of Management. A total of 50 respondents from various faculties at UTM are included in this research. All primary data have been obtained through the distribution of questionnaires. The questionnaire forms are used to gain information about the research that's ebbing carried out. The questionnaire forms consist of four parts, which is part A, B, C and D. Part A consists of the personal information and background of the students that I am surveying. Part $\mathrm{B}$ contains the part of the importance of effective communication. Part $\mathrm{C}$ includes the aspects of effective communication which are divided into four parts, C1- Proxemics, C2- Kinecis, C3- Paralinguistic, and C4- Chronemic (Mohanaraj, 2003). The data analysis method that is done is based on qualitative analysis. The data analysis will be done via SPSS (Statistical Package for Social Science) version 16. The score will be analyzed and presented in a statistical selection clearly defines the results of this survey in an effective, brief and easier way. It also appropriates the primary data that is collected. 


\section{Results}

Table 1. Frequency and percentage for the importance of effective communication

\begin{tabular}{|c|c|c|c|c|c|c|c|}
\hline PART B & & Frequenc & $(\mathrm{F}) /$ Perc & ntage $(\%$ & & MEAN & TOTAL \\
\hline $\begin{array}{l}\text { The importance of effective } \\
\text { communication }\end{array}$ & 1 & 2 & 3 & 4 & 5 & & \\
\hline $\begin{array}{l}\text { 1. Effective communication plays an } \\
\text { important role in conveying the message } \\
\text { to colleagues in university. }\end{array}$ & $1 /-$ & $1 / 3.6$ & $34 / 57.1$ & $4 / 10.7$ & $6 / 28.6$ & 3.46 & $46 / 100 \%$ \\
\hline $\begin{array}{l}\text { 2. You use more effective } \\
\text { communication in the university. }\end{array}$ & - & $1 / 3.6$ & $22 / 50.6$ & $15 / 25.6$ & $8 / 20.2$ & 3.11 & $46 / 100 \%$ \\
\hline $\begin{array}{l}\text { 3. Effective communication is only } \\
\text { suitable for use in a particular situation. }\end{array}$ & $9 / 7.1$ & $10 / 23.68$ & $7 / 7.8$ & $17 / 56.7$ & $3 / 4.72$ & 3.61 & $46 / 100 \%$ \\
\hline $\begin{array}{l}\text { 4. You use more effective } \\
\text { communication } \\
\text { communication. }\end{array}$ & - & $5 / 10.75$ & $25 / 46.4$ & $11 / 32.1$ & $5 / 10.75$ & 3.11 & $46 / 100 \%$ \\
\hline $\begin{array}{l}\text { 5. Effective communication is easier to } \\
\text { understand. }\end{array}$ & $1 / 3.6$ & $1 / 3.6$ & $7 / 21.4$ & $20 / 42.9$ & $17 / 28.5$ & 2.96 & $46 / 100 \%$ \\
\hline Total of Mean & & & & & & 16.3 & \\
\hline Average of Mean & & & & & & 3.26 & \\
\hline
\end{tabular}

Approximately 34 students strongly agree that effective communication plays a vital role in conveying a message to their colleagues in university. This contributes to 57.10 percent of the total respondents. The majority of students have used effective communication in the university at a moderate level which comprises of 4 students which contributes 10.70 percent of the total respondents. Based on the data received, 10 respondents agree that effective communication is only suitable to be applied in certain situations. They contribute to 23.68 percent from the total percentage. Besides that, the researcher has found that the respondents utilized effective communication in a moderate level if compared to non-effective communication.

This gives the researcher a picture that the students in University Technology Malaysia have a balanced approach when interacting, using both forms of communication which are verbal and non-verbal communication in the university. This can be proved when 20 students answered the question that effective communication more easily understood from 46 respondents, with 42.90 percent of the total amount.

Table 2. Frequency and percentage of effective communication (chronemics)

\begin{tabular}{|c|c|c|c|c|c|c|c|}
\hline & \multicolumn{5}{|c|}{ Frequency $(\mathrm{F}) /$ Percentage $(\%)$} & \multirow[t]{2}{*}{ Mean } & \multirow[t]{2}{*}{ Total } \\
\hline C4: Chronemics & 1 & 2 & 3 & 4 & 5 & & \\
\hline $\begin{array}{l}\text { 20. Your negative view of people who are not } \\
\text { punctual. }\end{array}$ & - & $1 / 3.6$ & $26 / 57.1$ & $15 / 32.1$ & $4 / 7.1$ & 3.43 & $46 / 100 \%$ \\
\hline $\begin{array}{l}\text { 21. You feel angry when your partner does } \\
\text { not arrive on time. }\end{array}$ & - & $1 / 3.6$ & $23 / 46.4$ & $18 / 35.7$ & $4 / 14.3$ & 3.61 & $46 / 100 \%$ \\
\hline $\begin{array}{l}\text { 22. You feel guilty if do not arrive on time as } \\
\text { promised. }\end{array}$ & - & - & $20 / 21.4$ & $29 / 67.9$ & $7 / 10.7$ & 3.89 & $46 / 100 \%$ \\
\hline $\begin{array}{l}\text { 23. Different people with different orienting } \\
\text { time. }\end{array}$ & $1 / 3.6$ & $7 / 14.3$ & $28 / 64.3$ & $10 / 17.9$ & - & 2.96 & $46 / 100 \%$ \\
\hline $\begin{array}{l}\text { 24. Time is an important aspect of } \\
\text { communication }\end{array}$ & - & $1 / 3.6$ & $7 / 14.3$ & $28 / 64.3$ & $10 / 17.9$ & 3.96 & $46 / 100 \%$ \\
\hline 25. Your punctuality in the study. & - & - & $11 / 21.4$ & $24 / 57.1$ & $11 / 21.4$ & 4 & $46 / 100 \%$ \\
\hline Total of Mean & & & & & & 1.85 & \\
\hline Average of Mean & & & & & & 3.64 & \\
\hline
\end{tabular}


There are four main elements that were determined in effective communication, which are proxemics, kinesics, paralinguistic and chronemics. According to data collected, it can be seen that the element which has the highest mean paralinguistic. The highest aspect involves chronemics with highest average mean of 3.64. The aspect of chronemics is the effective communication which involves the aspects of time utilization. The students at University Technology of Malaysia strongly believe in the significance of time. Therefore time has become a vital aspect to the respondents. The aspect which rated the lowest mean is the aspect of kinesics. Kinesics comprises of the effective communication that involves the aspect of hand and body languages, facial expression, eye contact and touch. This aspect is the least important aspect in effective communication among the student of University Technology of Malaysia, Johor Bahru. This might be because of the age factor of the students from the 26-30, whereby they are more comfortable to use verbal communication and tend to apply non-verbal communication unconsciously. Besides that, the dominant ethnic in the students are Malays, therefore they have a strong courtesy in their communication. Proxemics is a type of comforting gesture (such as an arm around the shoulder) or greeting between close friends or loved ones (Hamilton \& Creel, 2011, pp. 104). Based on the data collected, the average mean for the effective communication element of proxemics is 3.57 . Based on the last two questions in this aspect, it can be seen that students in UTM prioritize their private space in the university and as well when communicating with their colleagues. There are 27 respondents who agreed to question 4 "The effective communication plays an important role in your daily interactions, and 26 respondents who agreed to question 5, "You are concerned with personal space when communicating with colleagues." The conclusion from the findings of this aspect of effective communication is space plays a vital role in the interaction of students with others. Kinesics consists of body movement, gestures, posture, facial expressions and eye contact fall with the board field of effective communication called kinesics (Blum, 1998). This element of effective communication rated the lowest average mean if compared to the other three elements, with an average mean of 3.47. Paralinguistic includes accents, emphases, vocal qualities, pitch, rate, pauses, silences, and anything that adds to the meaning we associate with the verbal (Anderson, 1999). Based on the results of the questionnaire that is involved with speech and verbal communication. Based on the data, 30 out of 46 respondents agreed to question 16, "You speak with a seamless voice when talking to your friends". Besides that, 26 respondents agreed to question 15," You say that is not polite if someone speaks with a strong voice tone". Question 17 mentions that "You agree that the smoothness important in conveying the message". 25 respondents agreed to this question. Based on the data analysis of this aspect, fluency and the tone of voice are vital in communication among their colleagues and with the others. Chronemics is the study of the utilization of time effective communication. Chronemics is the way we perceive time, structure our time and react to time as powerful communication tool. These aspects of effective communication obtained the highest average mean level of 3.64. based on the total respondents out of 46 students, 29 agreed to question 22," You feel guilty if do not arrive on time as promised". This shows that the students in UTM practice punctuality. This is because of their university nature. Students are provided with a fixed time allocation for each task, example the time they spend for studying. Besides that, 28 respondents agree that time is an important element in communication. Here we can conclude that time is the most vital factor for student. The findings of this research show that a positive facial expression portrayed by the supervisor will create a form of information to the student when completing or carrying out their task. This contributes to mean level of 4.11 which is also highest mean level. 25 out of 46 students agree to the question, featured contributing to 53.60 percent of the total percentages. This shows that a positive facial expression could increase the emotional level and increase their performance on transferring information. The second highest mean, this is in-line to the second highest mean of 3.89 or clearly said 24 students feel uncomfortable when their supervisor orders them with a high voice tone. This is because when the supervisor is given instructions with high tone, it creates a perception that the supervisor is unhappy or angry with the students. However, a supervisor should provide instructions in a high voice tone when giving orders or instructions regarding something important, or when there is a need to complete urgently. The lowest mean level is 2.64 that mention that students do not show or portray a negative facial expression to their supervisor when they are dissatisfied about the instructions or order given. This is because the students believe that they need to respect their supervisor as the leader of their department and instructions from leader must be obeyed. The result of this finding strongly clarifies that a positive facial expression that is portrayed by a supervisor when communicating non-verbally affects the transferring information of students in UTM. This is because; a positive facial expression is able to increase the spirit and loyalty of staff in completing their task efficiently and effectively. This in return increases the transferring performance of students in UTM.

\section{Discussion}

The question in section B (importance of effective communication) and C (aspects of effective communication) in the research questionnaire are adapted fully from Mohanaraj (2003). The research shows that effective 
communication plays a vital role in the respondents' life as well as their interaction. However, they rarely practice it in the university life. This may be because of the type of our respondents who are males between the ages 26-30 and who are majority of Malays. Apart from this, the respondents might be also not actually realized the existence of effective communication in their daily interaction as sometimes effective communication is used indirectly. Based on the analyzed data, the students practice effective communication in a moderate manner. This is because all four questions in this section rate highest in the moderate level. The question with the highest mean level is "Effective communication is only suitable to be used in certain situations." Out of 46 respondents, 17 respondents agreed to this statement. Since out of the 5 questions rated moderately by the respondents, researchers have concluded that the students in UTM use effective communication equally. Based on past research conducted by Mohanaraj (2003), he has conducted the data collection via questionnaire. The questions were in the form yes and no answers, while questions were divided into 5 based on Likert Scale, Strongly Agree, Agree, Moderate, Disagree and Strongly Disagree. According to the first question is section B, 34 respondents $(57.10 \%)$ feel that effective communication is moderately important in conveying a message to their colleagues: this is because they assume effective communication is equally important. This is followed by question 2 , where 22 respondents $(50.60 \%)$ also answered moderately to this question. Through this, it is obvious that they utilize effective communication at an equal proportion at university. This opposes to Mohanaraj (2003) who conducted the previous research based on a yes and no scale received the results that 94 respondents $(87.9 \%)$ agree that effective communication plays an important role in conveying a message to their colleagues at university. Nevertheless, 62 respondents (57.9\%) disagree that they use less effective communication at the university. The result of the previous research supports the findings; however the differences may be caused by their university environment and nature of their life.

The third question in section B, 17 respondents $(56.70 \%)$ agree that effective communication is only suitable to be used in certain situations. The findings are fully supported by Mohanaraj (2003). As an overall view, we can conclude that the findings of the research are supported by the previous research done by Mohanaraj (2003). The effective communication aspect of chronemics has the highest average mean level compared to the other three aspects of effective communication which is proxemics, paralinguistic, and kinesics. The average mean for the aspects of chronemics is 3.64. This is because of the nature of environment in university. This result in supported by the findings of Mohanaraj (2003). Generally more than half of the respondents from the research conducted by Mohanaraj (2003) agree that time is an important aspect in their daily interaction which is in line with the respondents who are students that agree punctuality is vital in carrying out their task. The second highest average mean of the effective communication aspects of paralinguistic with the average mean of 3.60. This is because based on the characteristics of voice tone, the level and tone of voice used when communicating influences the mood and emotions of another. This can be applied when their supervisor use a negative voice tone with the students that may lead to decrease in transferring information. Proxemic is the effective communication aspect comes third with the average mean of 3.57. Proxemics involves gestures and space in the effective communication feature. Since the majority of the respondents consists Malay males between the age of 26-30, space becomes a priority when they are interacting with others. Besides that they rarely utilize comforting gestures as they are in their life. Last but not least is kinesics with the average mean of 3.47. It has the lowest average mean compared to the other three aspects. This is because their life nature does not involve them to utilize touch and other physical gestures. Therefore it is inappropriate for students of different genders to practice this form of effective communication. This result is supported by Mohanaraj (2003). 76.6\% of respondents agree this in Mohanaraj research. According to the data collected in part D, 28 out of 46 respondents agree to question which says "Instructions given by the supervisor through a fast way of speaking will confuse you." This shows that the student in UTM believe that instruction and orders that are conveyed to them must be precise and clear. Besides that, 25 respondents agree that a positive facial expression displayed by transferring information. Based on the results of part d, 25 out of respondents are agreeing that they use body movements to communicate with foreigners or tourists. Lastly, 24 respondents agree that they feel uncomfortable when their supervisor instructs them with a loud voice tone.

\section{Conclusion}

This research has formed a few findings to support the model that was constructed. Based on the research that is conducted, effective communication was only utilized in certain situations by the students in UTM. In addition to that, the students in UTM only applied more the chronemics aspect of effective communication in their daily interaction in the life. This may be because of the nature of the environment as a student. Punctuality is an essential element for the undergraduate students. The students practice effective communication in line with verbal communication. The students also prioritize a positive facial expression and as well as an amiable voice 
tone when receiving instructions by the supervisors. Lastly as a supervisor, they must play an important role ensure that all their student understand their message whether verbal or non-verbal. In contrary to this, the employees must clearly and specifically understand all messages conveyed by their supervisor to avoid unnecessary misunderstanding and conflict. Finally, the students should take the responsibility to determine the external factors besides effective communication like environment, personality, and motivational levels that might affect the transferring information of the between students in University. This research was conducted among undergraduate students. Even though the research is still valid and reliable with the 46 respondents, that future research can be conducted in other sectors as manufacturing sectors, marketing and logistics. There may be a difference in the communication techniques; therefore their knowledge level may be different as well. Besides that, the potential research can be conducted on both verbal and non-verbal communication to determine which is most appropriate to be use in the environment of university at a non-managerial level. Future research can also be conducted on managerial-level students to determine effective communication effects on transferring information. Lastly, besides using questionnaires, the prospective researchers can also use interviews and observation techniques to increase the validity and reliability of this research.

\section{References}

Ahmadian, S., Rahmandoust, M., Abdul-Hamid, A. B., Chelliah, S., Munusamy, J., \& Anvari, R. (2011). International opportunity recognition through international trade intermediary networks in Malaysian SMEs. Australian Journal of Basic and Applied Sciences, 5(10), 635-648.

Anderson, D. (1999). The development of science concepts emergent from science museum and post-visit activity experiences: Students' construction of knowledge (Doctor of philosophy thesis, Queensland University of Technology, Brisbane, Australia).

Anene, M. (2006). Effectiveness of communication in administration. Abraka: Delta State University.

Anvari, R., Huzaid, N. S. B. J., Miri, S. A., \& Chermahini, S. H. (2013). Mediating effect of psychological contract in the relationship between learning and development initiatives and engineers' intention to stay. Review of European Studies, 5(5), 233-237. http://dx.doi.org/10.5539/res.v5n5p233

Berlo, D. K. (1960). The Process of Communication. New York, NY: Holt, Rinehart, and Winston.

Blum, A. (1998). The Private Language Argument. Epistemologia, 21.

Bovee, C. L., \& Thill, J. V. (1992). Business Communication Today. NY, NY: McGraw-Hill.

Hamilton, C., \& Creel, B. (2011). Communicating for Success. United States: Pearson Education Inc.

Hoy, W. K., \& Miskel, C. G. (1998). Educational administration theory, research and practice. U.S.A.: Random House.

Jacques, E. (1987). The changing culture of a factory. London: Tavistock Publications Ltd.

Jay, M. (1995). History of Communications (Science Discovery). New York: Thompson Learning.

Koontz, H., \& O’Donnell, C. (2005). Management: A systems and contingency analysis of managerial functions. New York: McGraw-Hill Book Company.

Lasswell, H. D. (1948). The Structure and Function of Communication in Society. In L. Bryson (Ed.), The Communication of Ideas (p. 37). New York: Institute for Religious and Social Studies, Jewish Theological Seminary of America.

Lesikar, R. V., Pettit, J. D., \& Darsey, N. S. (1999). Communication in business. London: Longman.

Merihue, W. V. (1980). Managing by communication. New York: McGraw-Hill.

Mohanaraj, M. A. (2003). Elements of Effective communications. N.Y.: Circlet Press.

Nagamani, D., \& Muthuswamy, P. (2013). Teacher's Professional Use of Information and Communication Technology in Secondary Schools in Tamil Nadu, India. International Education Studies, 6(12). 64-73. http://dx.doi.org/10.5539/ies.v6n12p64

Riley, W., \& Riley, J. R. (1959). Mass Communication and the Social System. In R. K. Merton, L. Broom, \& L. S. Cottrell, Jr. (Eds.), Sociology Today: Problems and Prospects (pp. 537-578). New York: Basic Books, Inc.

Roberts, W. R. (1924). Rhetorica. In W. D. Ross (Ed.), The Works of Aristotle (Volume XI, p. 1358). London: Oxford University Press.

Schramm, M. (1961). How communication works, the process and effects of mass communication (pp. 5-6). 
Urbana, Ill.: The University of Illinois Press.

Shannon C. F., \& Weaver, W. (1964). The mathematical theory of communication (p. 7). Urbana, Ill.: The University of Illinois Press.

Sundaram, H., \& Chang, S. F. (2000). Audio Scene Segmentation using Multiple Features, Models and Time Scales to appear in ICASSP. Proceedings of the Acoustics, Speech, and Signal Processing, IEEE Interternational Conference, 4, 2441-2444.

Thayer, L. O. (1991). Communication and communication systems. Homewood, Ill.: Irwin.

\section{Copyrights}

Copyright for this article is retained by the author(s), with first publication rights granted to the journal.

This is an open-access article distributed under the terms and conditions of the Creative Commons Attribution license (http://creativecommons.org/licenses/by/3.0/). 